\title{
Characterisation of unsaturated geotechnical properties of filtered magnetite tailings in a dry stack facility
}

\author{
N Amoah Karara Mining Ltd, Australia \\ W Dressel Wave International, Australia \\ AB Fourie The University of Western Australia, Australia
}

\begin{abstract}
Filtered tailings and dry stacking are gaining attention due to problems with slurry-deposited tailings facilities and consequent catastrophic failures around the world. Factors such as recent technological advancements in filtration, lack of water, regulatory pressures and societal demands are shifting focus towards dry stacking. With the growing attention to filtered tailings, a major challenge is the knowledge gap on unsaturated soil properties required to understand the performance of unsaturated tailings in the dry stack facility, especially the hydraulic and shear strength behaviours.

This paper presents details of investigations to characterise unsaturated properties of filtered tailings material in a large-scale dry stack facility located in a highly net positive evaporation area in Western Australia. Field and laboratory tests were conducted to understand (i) hydraulic and water retention/storage functions, and (ii) shear strength responses to relevant stress state variables.

Historical cone penetration tests with pore pressure measurements (CPTus) conducted annually between 2013 and 2017 consistently indicate negative pore pressures within the dry stack up to $25 \mathrm{~m}$ depth.

Soil water characteristic curves (SWCCS) developed from laboratory water retention tests show that the tailings material has a low air entry value and desaturates quickly under low matric suctions below $18 \mathrm{kPa}$ and enters residual zones around $70 \mathrm{kPa}$, reaching residual suctions at $100 \mathrm{kPa}$. The SWCCs suggest that the unsaturated tailings potentially maintain large matric suction and low hydraulic conductivity which may require a substantial amount of surface water flux over a period to dissipate it, and complement the CPTu results. The magnitude and duration of surface water flux on site may not be sufficient to dissipate the large matric suctions due to short, low and infrequent rainfall and high evaporation rates over a long dry summer.

Triaxial and direct shear test results also indicate the significant difference between shear strength responses of saturated and unsaturated tailings to stress state variables (net normal stress and matric suction). For the saturated tests, the tailings shear stress response to the relevant stress state variable (net normal stress) is fairly linear. However, for the unsaturated tailings, plots of shear stress versus matric suction show non-linearity (curvilinear shape) in the failure envelope and higher shear strength results from matric suction compared to net normal stress.

The investigations have provided insights into the water storage characteristics and shear strength responses of the filtered tailings to stress state variables and sheds light on why the dry stack maintains unsaturated conditions. Steep stack angles up to $44^{\circ}$ observed on site are due to matric suction. For filtered tailings with a low air entry value and located in low rainfall areas with high evaporation, permanency of matric suction may develop to govern dry stack hydraulic and shear strength performance.
\end{abstract}

Keywords: filtered tailings, dry stack, unsaturated soils 


\section{Introduction and background}

Tailings storage facilities (TSFs) have conventionally been designed to contain slurry-deposited tailings with solids contents ranging between $25 \%$ and $60 \%(\mathrm{w} / \mathrm{w})$. Problems associated with the low densities and large volumes of water released from such TSFs have contributed to catastrophic failures around the world. To reduce tailings storage problems associated with water, high-density paste tailings with solids contents between $60 \%$ and $70 \%(\mathrm{w} / \mathrm{w})$ have been adopted in some projects. Other methods involve accelerated or forced drying of in situ tailings. Although these approaches have provided significant improvements, the tailings are still deposited at very high moisture contents, typically above liquid limit (LL) and in saturated conditions. In the past, improvement methods such as filtered tailings have been limited by technological inefficiencies and high costs. However, filtered tailings have great potential to provide safe storage even without containment embankments. This concept is often termed 'dry stacking'.

In recent years, filtered and dry stack tailings have been gaining attention due to (i) improvement in filtration technology for cost-effective filtration, (ii) increasing shortage or lack of suitable water for mining operations in dry areas, (iii) restrictions by regulatory authorities on water allocated for mining operations, (iv) regulatory and societal demands in response to catastrophic failures of wet tailings facilities, and (v) increasing recognition of lower lifecycle costs for dry stack facilities.

All these factors were crucial for the economic and operational viability of the Karara Iron Ore Project in Western Australia and therefore Karara Mining Limited (KML) adopted filtered tailings and dry stacking as the main tailings management approach in 2012. Karara Mining Limited's choice for filtered and dry stack tailings represented a novel approach in the Australian mining industry.

\subsection{Knowledge gap in filtered tailings and dry stacking}

With the growing attention to filtered tailings, a major challenge is the lack of understanding of the geotechnical performance parameters of a dry stack facility, mainly due to the limited number of operations in Australia and worldwide. Significant knowledge exists on slurry and paste or thickened tailings and the saturated soil mechanics theories underlying the design and operation of conventional wet tailings storage facilities are very well understood and applied. In Australia, comprehensive and strict regulatory guidelines exist for the design, construction and operation of tailings facilities in all states, and the Australian National Committee on Large Dams (ANCOLD) also provides comprehensive technical guidance documents (e.g. ANCOLD 2012). However, virtually all these documents focus on conventional wet tailings facilities with some coverage of high-density thickened tailings. Advancements in dry stacking will require a similar level of understanding of unsaturated soil mechanics principles, especially the hydraulic and shear strength behaviour of unsaturated filtered tailings in situ and under service conditions.

In the field of tailings storage facilities (TSFs), the literature on filtered and dry stack tailings is very limited and the problem becomes even more confusing due to the uncontrolled use of the dry stacking terminology. The works of Lupo et al. (2010) and Davies (2011) are among a few in the literature that provide some practical insights and some technical basis for designing dry stack facilities.

\subsection{Dry stack tailings material}

It is important to attempt a clarification of what constitutes dry stack material as the terminology is often confusing. In a general sense, tailings material that is filtered and deposited at moisture contents below the liquid limit may be considered as falling within the dry stacking, but in the stricter sense, dry stacking applies to tailings filtered and deposited at moisture contents at or below the plastic limit (PL). Such tailings materials have distinctive characteristics including (i) moisture contents that are closer to standard optimum moisture contents $(\mathrm{OMC})$ and therefore compacts to higher densities in situ than conventional slurry tailings, (ii) have a lower degree of saturation and compressibility at deposition and tend to remain so, (iii) can be stored without external containment embankments and (iv) can be transported by trucks or mechanical conveyors. 
A key performance requirement of dry stack TSFs is the ability of the in situ tailings to remain unsaturated and retain low compressibility in order to provide superior hydraulic and shear strength characteristics to withstand service loading (static and seismic) without containment embankments.

\subsection{Filtered tailings and dry stacking at the Karara operation}

Karara Mining Limited is a joint venture between Ansteel, China and Gindalbie Ltd, Australia. Karara Mining Limited owns a magnetite iron ore operation in the mid-west region of Western Australia (a highly net positive evaporation area with an annual evaporation to rainfall ratio of around 10:1). The operation consists of the magnetite mine, process plant, rail, port and infrastructure for production and export of magnetite. The plant was commissioned in 2012, followed by production ramp-up to name plate production of $8 \mathrm{Mtpa}$ in 2016. A unique feature of Karara's operation is the production of filtered tailings and operation of a dry stack tailings facility, which are not common in the Australian mining industry.

The production of magnetite ore and associated tailings generally involves conventional crushing, screening, milling and a series of magnetic separation steps followed by thickening and filtration. The final magnetite concentrate with a design grade up to $68 \% \mathrm{Fe}$ is then stockpiled before being loaded into rail wagons and transported to the port of Geraldton, Western Australia for export. The non-magnetic tailings from the magnetic separation processes and reverse flotation process are combined in a common thickener for water recovery prior to pressure filtration. This is followed by pressure filtration stage using Outotec filters to recover the remainder of the recoverable free water leaving a filter cake containing around $15 \%$ moisture $(\mathrm{w} / \mathrm{w})$. The resulting filtered tailings with a homogeneous consistency are then transported via overland conveyors (Figure 1(a)) for dry stacking in a dedicated dry stack tailings facility.

The filtered tailings are stored in a radial pattern called sweeps (Figure 1(b)) using mechanical conveyors designed and installed by FLSmidth. The tailings operation is managed by Bis Industries under a contract agreement with KML. Details of the tailings production, conveying and stacking processes are discussed in Amoah (2017), but Figures 1 (a) to (e) provide further insight from tailings conveying to stacking.

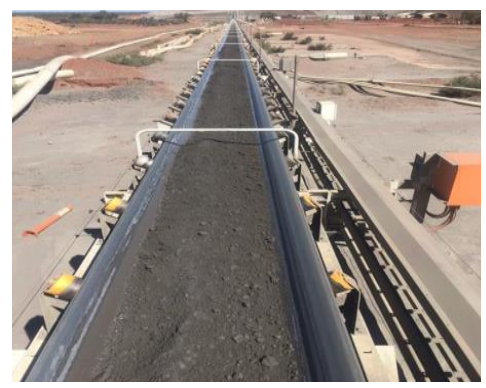

(a)

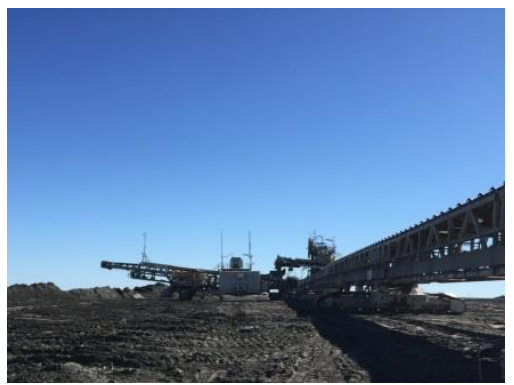

(d)

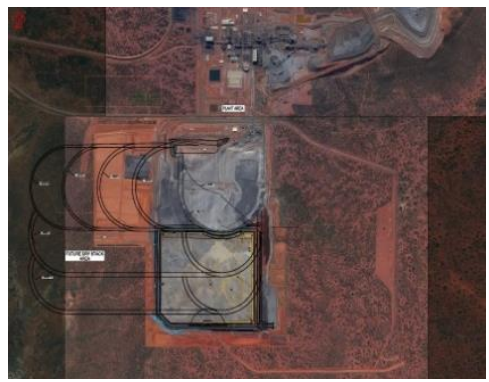

(b)

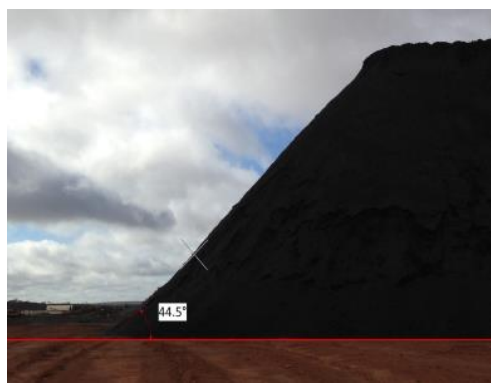

(e)

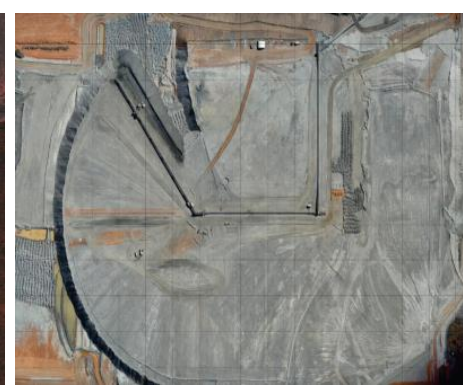

(c)

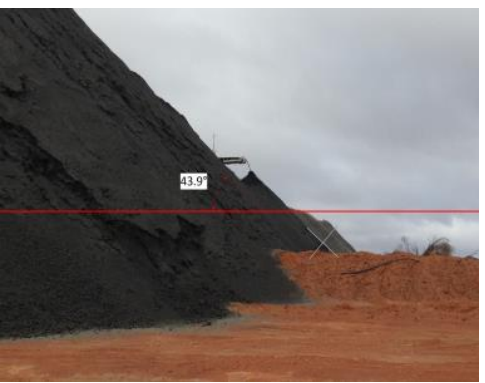

(f)

Figure 1 (a) Filtered tailings conveying; (b) Dry stack (sweeps); (c) Radial stacking; (d) Conveyor operation; and, (e) Typical tailings stacking angles onsite (note steep angles) 


\subsection{General properties of filtered magnetite tailings at Karara}

Numerous geotechnical tests have been conducted on the magnetite tailings material since 2013 as part of various investigations and geotechnical design. Field tests include cone penetration tests (to full depth) with pore pressure measurements (CPTus) which have been conducted annually between 2013 and 2017. CPTu test results have consistently indicated negative pore water pressures within the dry stack. Laboratory tests include basic properties such as particle size distribution (PSD), liquid limit (LL), plastic limit (PL), plasticity index (PI), shrinkage limit (SL), strength and compressibility tests (direct shear, triaxial, oedometer, Rowe cell, etc.). Results indicate that the tailings material is predominantly silt, with very low plasticity (LL 26-28, PL 17-20) and standard optimum moisture (OMC) $13 \%$ to $15 \%$. A summary of the engineering properties is provided in Amoah (2017). It must be noted that all the consolidation and strength tests to date were undertaken to provide saturated geotechnical properties on the assumption that saturated properties provide conservative parameters for design.

\section{$2 \quad$ Saturated and unsaturated soils}

\subsection{Soil air and water content effects}

Partially saturated soil exists as a multiphase material in the form of an air-water-solid system. The void spaces in the soil mass may be filled with water and/or air. The key factor in geotechnical analyses is to understand how the water and air in the void spaces combine to influence the shear strength and hydraulic behaviour of the soil in situ. The water content is expressed in various forms such as (i) volumetric water content, $\theta\left(\theta=V_{\text {water }} / V_{\text {total }}\right)$, (ii) gravimetric water content, $w\left(w=M_{\text {water }} / M_{\text {solid }}\right)$, and (iii) degree of saturation, $\mathrm{S}\left(\mathrm{S}=\mathrm{V}_{\text {water }} / \mathrm{V}_{\text {voids }}\right)$. These parameters are commonly related to available void spaces in the soil that may be expressed as void ratio e $\left(e=V_{\text {voids }} / V_{\text {solids }}\right)$ or porosity $n\left(n=V_{\text {voids }} / V_{\text {total }}\right)$. Water content analyses are commonly used in metallurgy, soil physics, agricultural science, geotechnical engineering, etc. but are sometimes used differently. The above expressions (Fredlund \& Rahardjo 1993) are used in geotechnical engineering and this paper.

The degree of saturation (S) is the basic parameter used to distinguish between saturated and unsaturated soils: (i) saturated soils have a $100 \%$ degree of saturation $(S=100 \%)$, i.e. all voids are filled with water, (ii) unsaturated soils have degree of saturation less than $100 \%(S<100 \%)$, i.e. the void spaces are filled with water and air in varying proportions, and (iii) dry soils have zero degree of saturation $(S=0)$, i.e. all void spaces are filled with air.

\subsection{Stress state of saturated and unsaturated soils}

Fredlund and Morgenstern (1977) observed that the shear strength of soils is related to the stress state in the soil, a term that consists of a certain combination of state variables (termed stress state variables) that are independent of material properties. In saturated soil mechanics, only the stress from load application, i.e. net normal stress, is considered. Therefore, effective stress is the only variable used to define the state of stress (one stress state variable). However, for unsaturated soils the number of stress state variables depends on the degree of saturation.

Applying the concept of stress state variables, Ho and Fredlund (1982), Fredlund and Rahardjo (1993), Vannapali et al. (1996), and Zhou et al. (2016) have all observed the significant differences between saturated and unsaturated soils in terms of how changes in water and air phases affect soil hydraulic conductivity. Similar effects on shear strength have been reported by the above workers and a disquisition on this has been provided by Fredlund and Rahardjo (1993). Kim et al. (2016) recently studied the effects of the degree of saturation on decomposed granitic soils with varying fines contents (fines of 10, 25 and 40\%) and varying degrees of saturation between 50 and $80 \%$ and concluded that as the degree of saturation decreases, compressive strength increases regardless of the fines content. These findings are consistent with conventional theories of soil mechanics, where the presence of water in the void spaces acts to reduce the extent of inter-particle contact forces through the concept of pore water pressure when the soil is 
saturated. Failure is commonly expressed in terms of the Mohr-Coulomb criterion which states that when the ratio of the shear stress to normal stress at any plane reaches a critical value, the soil fails. In unsaturated soils, the application of matric suction causes a reduction in water content and allows pore spaces to be filled with air, creating two phase conditions. Two stress state variables therefore exist, i.e. net normal stress and matric suction, and both are required to characterise the shear strength. Hence, the conventional Mohr-Coulomb failure criteria based on a single stress state variable is not sufficient for characterising shear strength.

Fredlund and Rahardjo (1993) provide a detailed analysis and graphical representation of the nature of the Mohr circle of unsaturated soil. In their approach, the Mohr circle corresponding to the failure conditions are plotted in three-dimensional space with shear stress as ordinate and the two stress state variables (net normal stress, $\left.\sigma-u_{w}\right)$ and matric suction $\left(u_{a}-u_{w}\right)$ as abscissas. The resulting Mohr circle is referred to as the extended Mohr circle or extended Mohr-Coulomb failure envelope for unsaturated soils, from which shear parameters for the stress state variables are obtained.

\subsection{Effects of stress state variables - matric suction and water storage functions}

Fredlund and Rahardjo (1993) noted that in saturated soils the hydraulic conductivity is directly influenced by the void ratio, but in unsaturated soils the hydraulic conductivity is directly influenced by a combination of void ratio and degree of saturation. However, changes in the degree of saturation or water content have more significant effect in unsaturated soils. Conventionally, water does not easily flow through pore spaces filled with air, but rather through interconnected pore spaces filled with water. As more void spaces are filed with air, water flow through the interconnected pore spaces reduces even if the overall void volume remains the same.

In practice, the major factor affecting the volume of water and air in the soil pore spaces is the matric suction and the distribution (and size) of pores in the soil. Matric suction represents the pressure dry soil exerts on the surrounding soils in an attempt to maintain moisture content equilibrium. It is the difference between the pore air pressure $u_{a}$ and the pore water pressure $u_{w}$, i.e. $u_{a}-u_{w}$ (Lu 2008). Lu (2008) also explained that matric suction represents the soil water pressure deficit with respect to air pressure or the soil water potential deficit with respect to the soil water potential at ambient pressure. For example, $1 \mathrm{kPa}_{\mathrm{a}}$ of matric suction indicates that the soil water pressure is $1 \mathrm{kPa}$ below the ambient air pressure or $1 \mathrm{KJ} / \mathrm{m}^{3}$ of pressure potential below the water pressure potential.

\subsection{Soil water characteristic curves}

When suction is applied to a soil, the soil undergoes drying as moisture loss occurs and air begins to fill the void spaces. Similarly, as dry soils gradually take on water/moisture, the soils undergo wetting as the pore spaces are gradually filled with water and more and more air is displaced. Accompanying these processes are changes in volume, strength and hydraulic characteristics of the soil. The relationship between the matric suction and changes in soil water within the soil is expressed graphically as the soil water characteristic curve (SWCC). The SWCC has two curves representing the drying and wetting responses of the soil and these are always different for the same soil, i.e. shows hysteresis, the extent of which depends on the type of soil. The SWCC was pioneered in the fields of soil physics and agricultural science where it is commonly termed the moisture characteristics curve (MCC), water retention curve (WRC) or moisture retention curve (MRC) and has been adopted in geotechnical engineering for the analysis of unsaturated soils. The SWCC provides key information on (i) desaturation characteristics of the soil as it under goes drying, (ii) the air entry value (AEV), (iii) residual suction and degree of saturation, and (iv) hydraulic behaviour of the soil (Fredlund et al. 1996).

The AEV and residual degree of saturation are very important parameters for engineering analyses. The AEV is the matric suction at which the soil starts to desaturate and air starts to enter the pore spaces of the previously saturated soil. Prior to reaching the AEV, all the pore spaces are filled with water (saturation state). Beyond the AEV, the soil basically enters the unsaturated state and continues to desaturate with further increase in matric suction until it reaches a state where further increase in suction is no longer 
accompanied by further changes in degree of saturation. This point is termed the residual degree of saturation. The transitional zones depicted by the SWCC are shown in Figure 2 (Kohgo 2003) and provide the conceptual understanding and the complete profile of the soil from saturation to the final dry state.

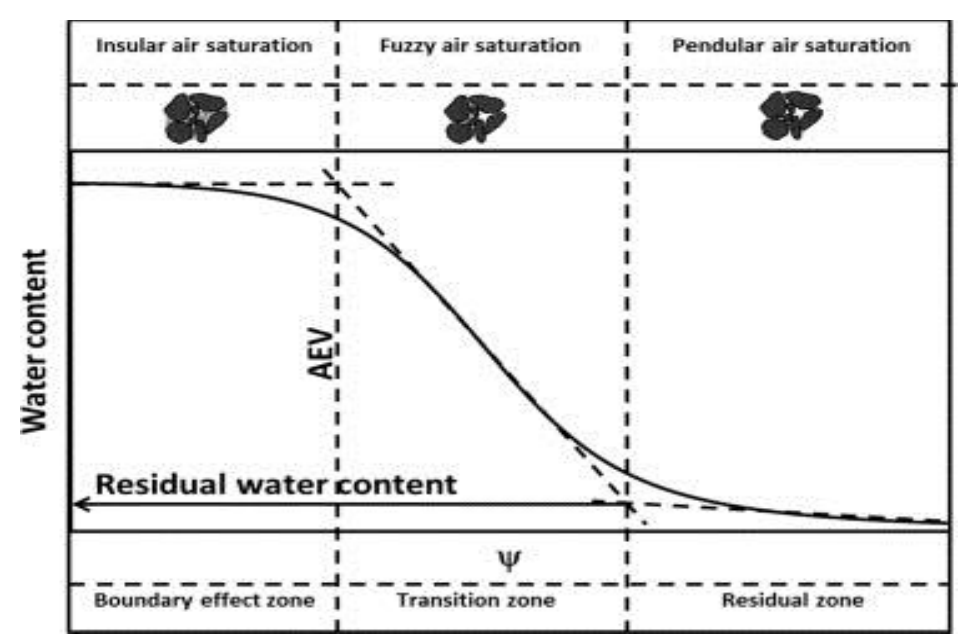

Figure 2 Soil water characteristics curve - transition zones (Kohgo 2003)

\subsection{Effects of stress state variables on shear strength}

Fredlund and Morgenstern (1977) first introduced the concept of stress state variables for interpreting the engineering behaviour of unsaturated soils. The two stress state variables used are net normal stress $\left(\sigma-u_{a}\right)$ and the matric suction $\left(u_{a}-u_{w}\right)$. Fredlund et al. (1978) used the stress state variable concept to propose the shear strength equation for unsaturated soils in Equation 1:

$$
\tau_{f}=c^{\prime}+\left(\sigma-u_{a}\right) \tan \phi^{\prime}+\left(u_{a}-u_{w}\right) \tan \phi^{b}
$$

where:

$$
\begin{array}{ll}
\left(u_{a}-u_{w}\right) \tan \phi^{b} & =\text { the shear strength contribution due to matric suction. } \\
\tau_{f} & =\text { shear strength of an unsaturated soil. } \\
c^{\prime} & =\text { effective cohesion of the soil. } \\
\phi^{\prime} & =\text { effective angle of shearing resistance for saturated soil. } \\
\sigma & =\text { the total stress. } \\
\left(\sigma-u_{a}\right) & =\text { net normal stress. } \\
u_{a} & =\text { pore air pressure. } \\
u_{w} & =\text { the angle of internal friction with respect to matric suction. }
\end{array}
$$

Equation 1 shows that the shear strength is increased by matric suction when the soil is unsaturated. The matric suction component $\left(\left(u_{a}-u_{w}\right) \tan \phi^{b}\right)$ is sometimes termed as apparent cohesion (Kim et al. 2016). Vanapali et al. (1996) modified Equation 1 to Equation 2 in terms of degree of saturation:

$$
\tau=\left[c^{\prime}+\left(\sigma_{n}-u_{a}\right) \tan \phi^{\prime}\right]+\left[\left(\frac{S r-S r 0}{1-S r 0}\right)\left(u_{a}-u_{w}\right)\left(\tan \phi^{\prime}\right)\right]
$$

where:

$$
\begin{aligned}
& S r \quad=\text { degree of saturation. } \\
& S r 0 \quad=\text { residual degree of saturation. }
\end{aligned}
$$


Equation 2 avoids the use of fitting parameters developed by Fredlund and Xing (1994) to obtain $\phi^{b}$ and allows for more parameters to be obtained from the SWCC.

Gan and Fredlund (1996) studied the saturated and unsaturated shear strength properties of two saprolitic soils using direct shear tests and triaxial tests and reported that the relationship between matric suction and shear strength takes on a nonlinear form. They observed that the extent of increase in shear strength with matric suction is related to the SWCC and the amount of dilation occurring during shear.

The manner in which filtered tailings behave at various degrees of saturation and range of suctions onsite are fundamental to understanding dry stack facilities. Field investigations combined with unsaturated parameters from laboratory tests are required to quantify the water storage and shear strength functions.

\section{Laboratory determination of unsaturated properties of filtered tailings}

Dry stacking basically involves the storage of filtered tailings in an unsaturated state. Therefore, critical information on hydraulic and water storage functions, shear strength and volume change functions for engineering analyses all require laboratory tests for unsaturated soil properties. For example, a good understanding of the effect of matric suction applied over a wide range relevant to the site conditions is very important for analysing the dry stack tailings mass. Knowledge of water storage functions will determine whether the dry stack facility will build up water to create a phreatic surface and thus positive pore pressures which may affect shear strength and structural stability.

All laboratory tests were conducted at E-Precision Laboratory (an accredited laboratory in Perth). Although the focus of the laboratory test work was to assess the unsaturated properties of the magnetite tailings, the testing program was developed to cover saturated tests to provide a direct comparison between saturated and unsaturated properties where necessary. The testing regime was divided into several parts to cover a range of suction pressures and stress state conditions. Tests conducted included (i) basic properties, e.g. PSDs, Atterberg limits (LL, PL, PI, SL), standard maximum dry density (MDD) and OMC, and (ii) unsaturated and saturated triaxial and direct shear tests, and (iii) soil water storage and retention tests.

\subsection{Test for basic and index properties of magnetite tailings}

The results of index properties and PSD tests of the tailings are summarised in Table 1, and the PSD curves are shown in Figure 3. There is no significant difference between the Atterberg limits of colluvium and tailings, although the colluvium is coarser and has more clay-size particles.

Table 1 Basic and index properties of magnetite tailings

\begin{tabular}{llllllllll}
\hline $\begin{array}{l}\text { Material } \\
\text { property }\end{array}$ & LL & PL & PI & SL & \% silt & \% clay & $\begin{array}{l}\text { Specific } \\
\text { gravity }\end{array}$ & $\begin{array}{l}\text { Initial bulk } \\
\text { density }\left(\mathbf{t} / \mathbf{m}^{3}\right)\end{array}$ & $\begin{array}{l}\text { Initial } \\
\text { moisture }\end{array}$ \\
\hline Tails sample 1 & 25.2 & 20.6 & 4.6 & 19.0 & 74.5 & 7.5 & 2.94 & 2.10 & 12.2 \\
Tails sample 2 & 26.0 & 18 & 8 & 18.1 & 70 & 5 & 3.01 & 2.1 & 13.54 \\
Tails sample 3 & 25.6 & 19.9 & 5.6 & 18.2 & 83.4 & 7.0 & 3.0 & 2.1 & 11.05 \\
Colluvium soil & 24.1 & 17.9 & 6.2 & 16.1 & 37.7 & 11.5 & 2.7 & - & 28 \\
\hline
\end{tabular}




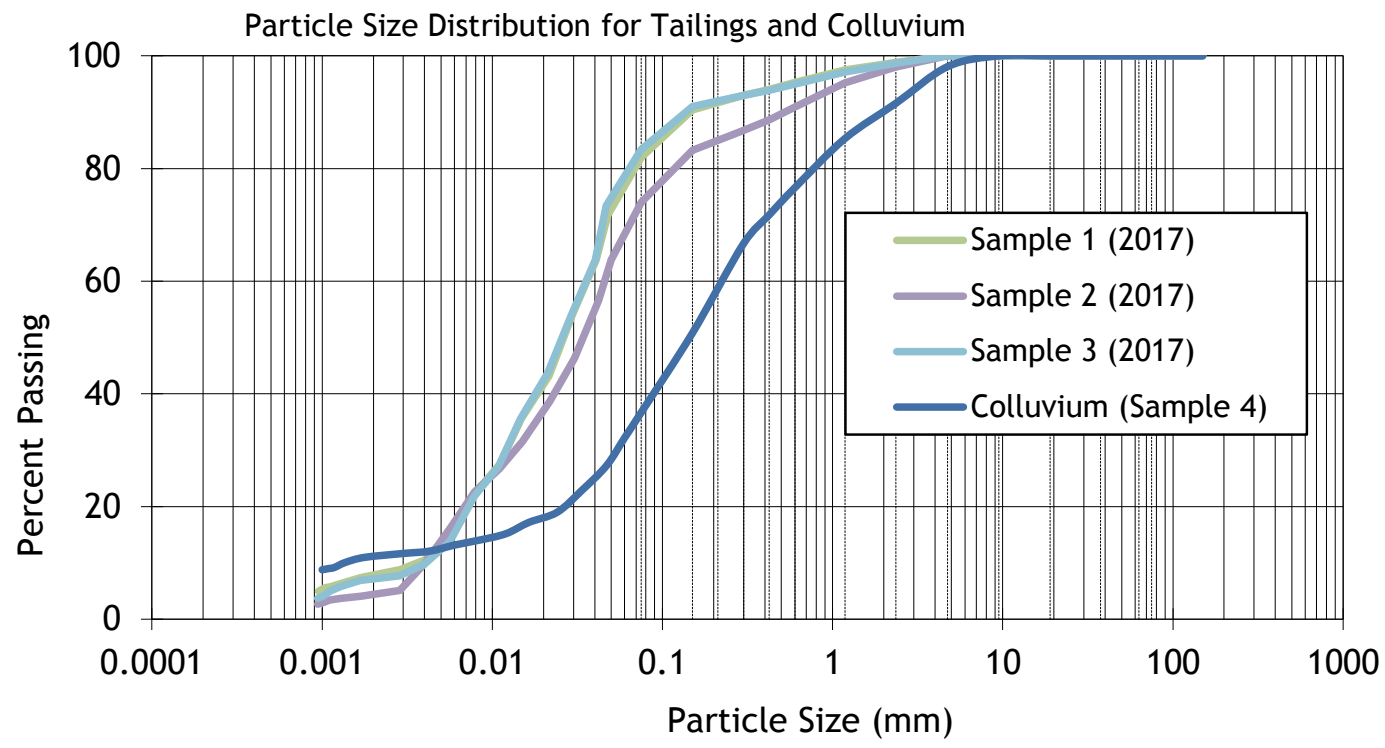

Figure 3 Particle size distribution curves for magnetite tailings and site colluvium material

\subsection{Determination of soil water characteristic (retention) curve for filtered tailings}

In practice, the tailings in the dry stack facility undergo drying and wetting phases in summer and winter. Understanding the water storage functions and hydraulic conductivity of the in situ tailings is very important for assessing how quickly the tailings material will desaturate in summer or saturate in winter and whether there is permanency of matric suction to maintain unsaturated conditions.

Laboratory tests to determine water storage or retention properties of the magnetite tailings were conducted on samples (samples 1,2,3) collected from different areas of the existing dry stack for materials produced between 2014 and 2017 including a freshly produced material collected from the conveyor belt in April 2017. A fourth sample (from sample 2) was modified at the lab to produce slurry, similar to wet-deposited tailings, prior to testing. It was assumed that the slurry sample will not undergo significant volume change due to the silty and very low plasticity nature. Matric suctions up to $400 \mathrm{kPa}$ were applied to the samples and changes in water content were determined based on measurements of volume of water expelled from samples. Gravimetric water contents and degree of saturation were computed based on water losses/retentions associated with the application of matric suction.

Although the colluvium material was not part of the scope of investigation, samples of colluvium material were tested to compare its water retention properties with the tailings. Figures 4(a) and (b) show the SWCC for the tailings samples and the colluvium respectively. The AEV of the tailings estimated from the drying curves is around $15-18 \mathrm{kPa}$. The SWCCs show that the moisture content decreases at a very slow rate under low suction and decreases rapidly after the AEV is exceeded. The rate of desaturation of the tailings appears to be very high between the AEV and suction pressures around $70 \mathrm{kPa}$, after which it enters the residual zone and stabilises to residual suctions after $100 \mathrm{kPa}$. After the AEV, no significant difference is noted in the rate of desaturation of slurry and non-slurry samples. Figure $5(\mathrm{a})$ shows the volume of tailings water discharged due to matric suction and Figure 5(b), the corresponding degree of saturation.

The AEV of the tailings is relatively low and desaturation begins at low suction pressures around $15 \mathrm{kPa}$. The drying and wetting curves are clearly different, with all the wetting curves below the drying curves, confirming the hysteretic nature of the SWCC. However, the drying curve is commonly used in interpretation of unsaturated soil conditions (Fredlund et al. 2001) and is adopted in this analysis. 


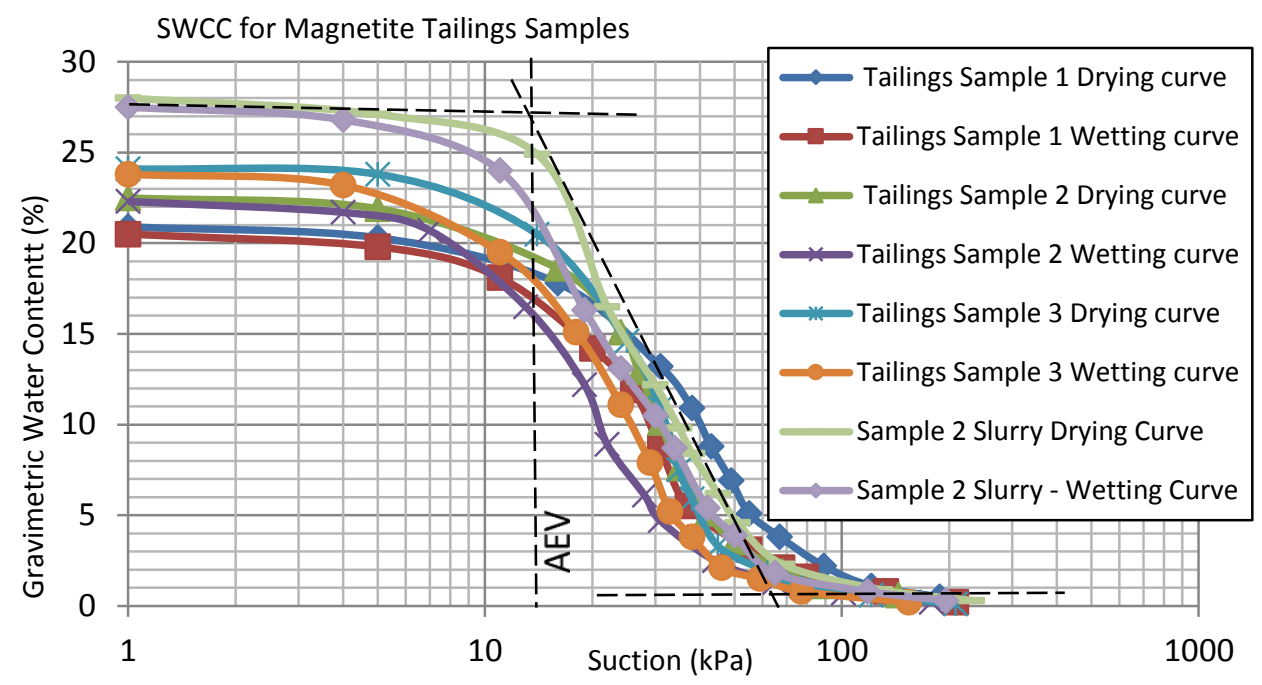

(a)

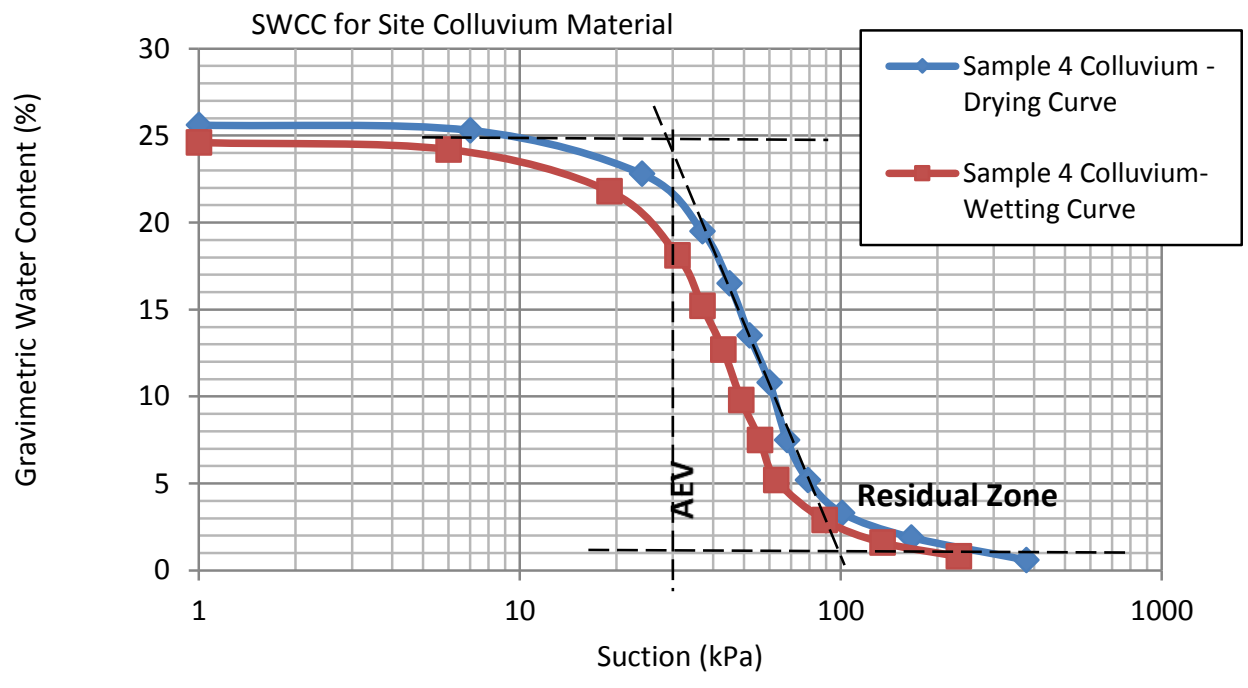

(b)

Figure 4 Soil water characteristic (retention) curves; (a) Magnetite tailings; and, (b) Colluvium material

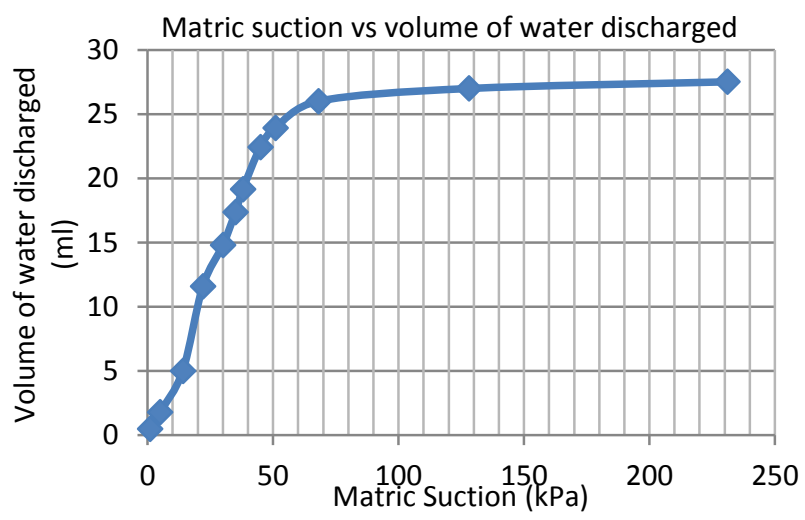

(a)

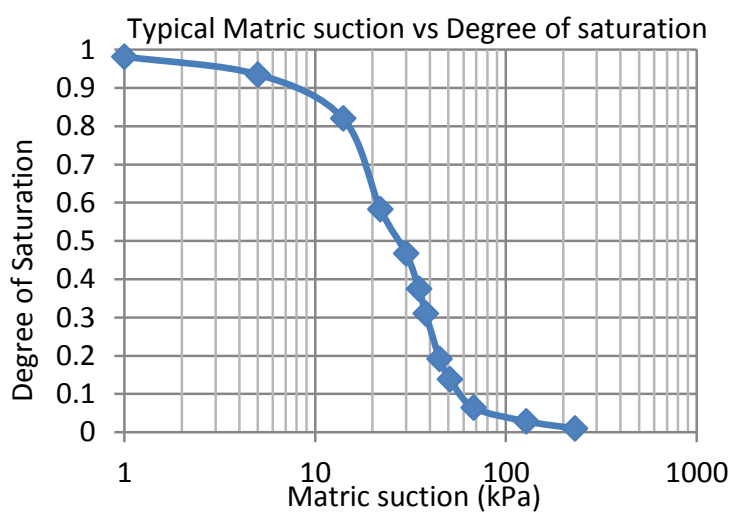

(b)

Figure 5 (a) Matric suction and volume of water discharged; and, (b) Typical degree of saturation curve 
Comparing Figures 4(a) and (b) clearly shows the differences in the water retention/storage characteristics of the tailings and colluvium materials. The AEV of the colluvium is around $30 \mathrm{kPa}$ (which is about twice that of the magnetite tailings) and enters the residual zone after $100 \mathrm{kPa}$ and stabilises to residual suctions around $200 \mathrm{kPa}$. Hence, the tailings material will start to desaturate much quicker under the same conditions onsite. The tailings SWCCs suggest that large values of matric suction exist within the unsaturated filtered tailings in the dry stack, and hence negative pore water pressures will not easily dissipate. The large matric suctions may need a large amount of ground surface water flux over a long period to dissipate it, which is reflected in the CPTu results obtained to date.

\section{$4 \quad$ Laboratory tests for saturated and unsaturated shear strength of filtered tailings}

All tests were conducted at E-Precision Laboratory. Both the direct shear and triaxial shear tests equipment allow for control of pore air and pore water pressures. The equipment set-up is similar to Figure 6(a) (Ho \& Fredlund 1982, triaxial test) and Figures 6(b) and (c) (Schnellman et al. 2013, direct shear) under controlled matric suction using the axis translation method. Pore water pressure is controlled through air entry disc at the base of the specimen that allows water flow through the disk for continuous collection of water.

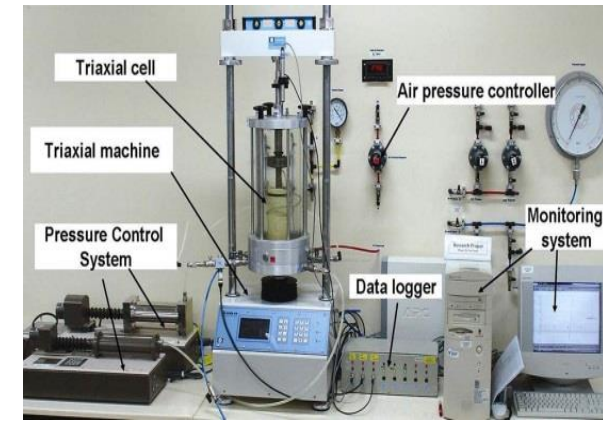

(a)

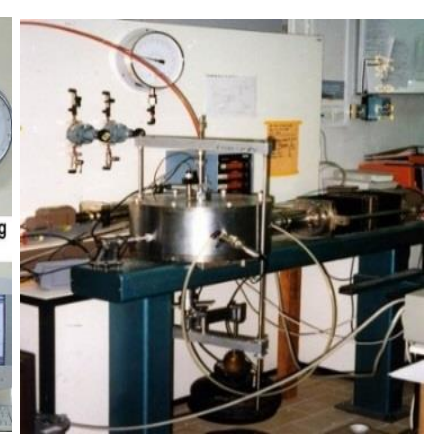

(b)

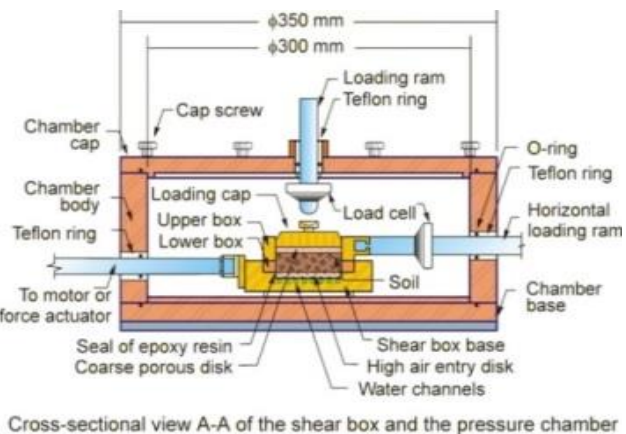

(c)

Figure 6 (a) Modified triaxial (Ho \& Fredlund 1982); (b) and (c) Modified direct shear (Schnellman et al. 2013)

\subsection{Saturated triaxial tests on magnetite tailings}

Multistage triaxial tests were conducted on saturated and unsaturated magnetite tailings samples (reconstituted samples). All the saturated soil tests were undertaken using a conventional triaxial cell for obtaining shear strength parameters as described in the literature. During the test, confining stresses $\left(\sigma_{3}\right)$ of 50, 100 and $150 \mathrm{kPa}$ were used. The results are shown in Figure 7 . The point of interest is the near-linear relation between deviator stress, confining stress $\left(\sigma_{3}\right)$ and strain.
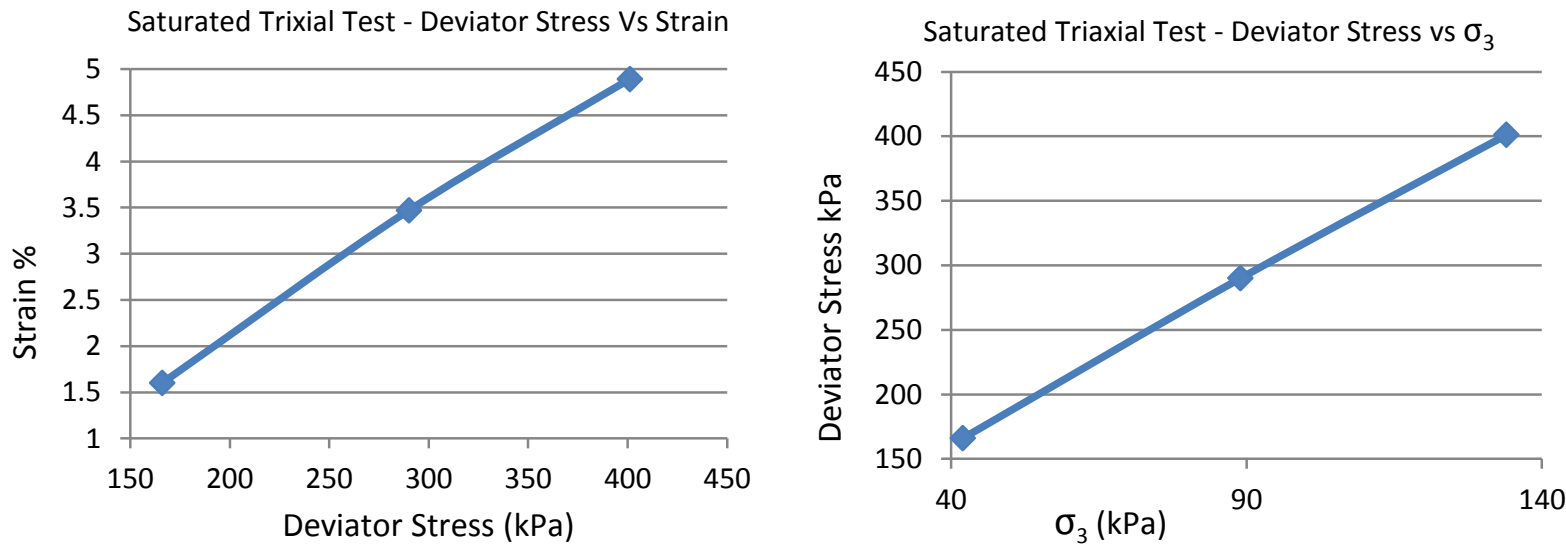

Figure 7 Results of saturated triaxial tests on magnetite tailings 


\subsection{Unsaturated triaxial tests on magnetite tailings}

The unsaturated triaxial tests were conducted in a modified triaxial cell for both air pressure and pore water control (Figure 6a). The triaxial test equipment has a porous ceramic disc with high AEV at the base of the sample to separate the pore air and pore water pressures. The stresses associated with the various stages were applied. A net confining pressure $\left(\sigma_{3}\right)$ of $100 \mathrm{kPa}$ was applied the shearing stage and matric suctions were varied from $50 \mathrm{kPa}$ to $300 \mathrm{kPa}$. The specimens were consolidated under the isotopic confining pressures and the maximum deviator stress (shear strength) and the matric suction were observed over the range applied. Water volume changes were recorded until no further increase in water collected and the specimen was considered to be in equilibrium. The shear stage data and stress measurements are summarised in Table 2 below. The matric suction versus deviator stress and axial strain are also shown in Figure 8 . The point of interest in Figure 8 is the nonlinear response of deviator stress and axial strain to matric suction.

Table 2 Shear stage data for unsaturated triaxial tests

\begin{tabular}{|c|c|c|c|c|c|c|c|c|}
\hline \multicolumn{9}{|c|}{ Shear stage data and stress measurements (kPa) } \\
\hline \multirow{2}{*}{$\begin{array}{l}\text { Material } \\
\text { property }\end{array}$} & \multirow{2}{*}{$\begin{array}{l}\text { Confining } \\
\text { pressure }\end{array}$} & \multirow[t]{2}{*}{$u_{w}$} & \multirow[t]{2}{*}{$u_{a}$} & \multicolumn{4}{|c|}{ Principal effective stresses } & \multirow[t]{2}{*}{ Strain (\%) } \\
\hline & & & & $\sigma_{1}^{\prime}$ & $\sigma^{\prime}{ }_{3}$ & $\sigma_{1}^{\prime} / \sigma^{\prime}{ }_{3}$ & $\sigma_{1}-\sigma_{3}^{\prime}$ & \\
\hline Shear stage 1 & 100 & 0 & 51 & 522 & 100 & 5.22 & 422 & 2.05 \\
\hline Shear stage 2 & 100 & 0 & 152 & 620 & 100 & 6.20 & 520 & 4.39 \\
\hline Shear stage 3 & 100 & 0 & 303 & 684 & 100 & 6.84 & 584 & 6.04 \\
\hline
\end{tabular}
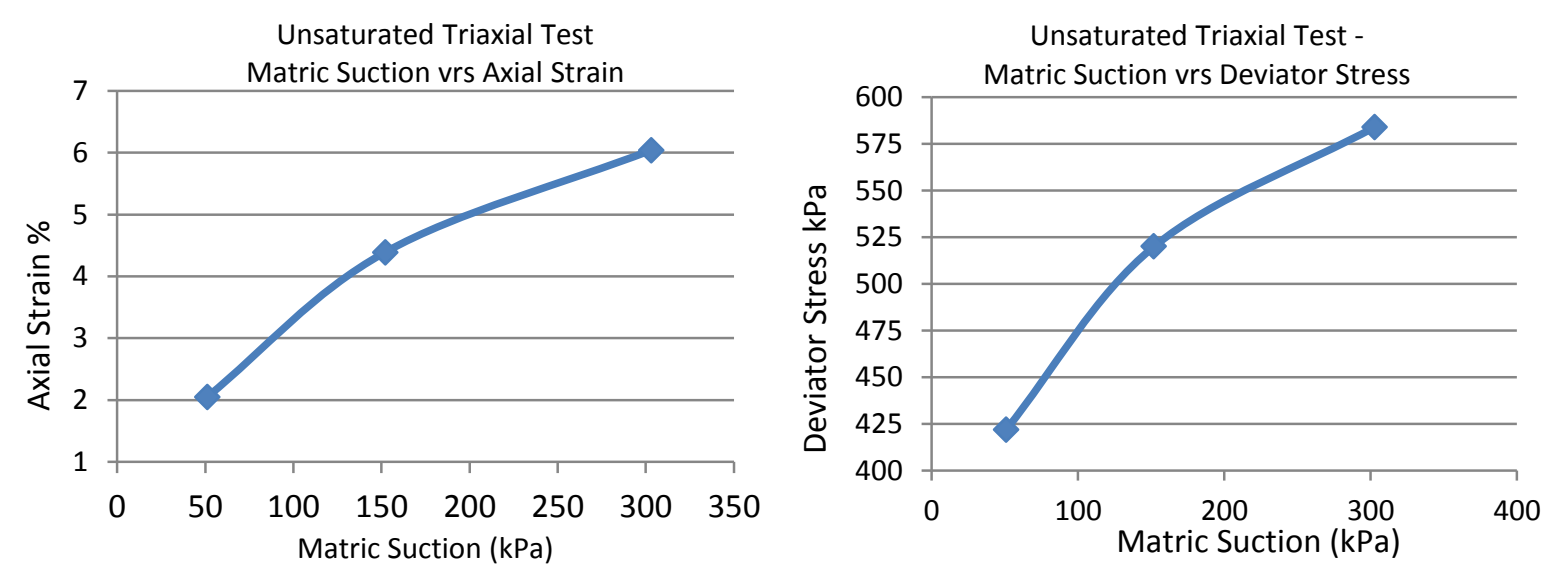

Figure 8 Results of unsaturated triaxial tests - relation between matric suction, stress and strain

\subsection{Direct shear tests for saturated and unsaturated magnetite tailings}

A number of single stage direct shear tests were conducted for both saturated and unsaturated tailings samples. The direct shear test takes less time and is relatively inexpensive compared to triaxial test, therefore, more tests on shear strength variations with matric suction were undertaken.

\subsubsection{Direct shear tests for saturated sample}

The direct shear test on saturated samples was undertaken using the conventional approach. Several plots were obtained including (i) shear displacement versus normal displacement, (ii) shear displacement versus effective shear stress and (iii) shear stress versus net normal stress shown in Figure 9. Peak shear stresses were used as the shear stress at failure and the line plotted through the points represents the Mohr-Coulomb failure envelope for the saturated specimen. The test results exhibit essentially linear failure envelopes with respect to net normal stress axis similar to what is commonly observed by others including Gan et al. (1988) in 
their study on compacted glacial till. The intercepts on the shear strength axis represent the effective cohesion c' and the gradient represents the effective friction angle as per conventional method.
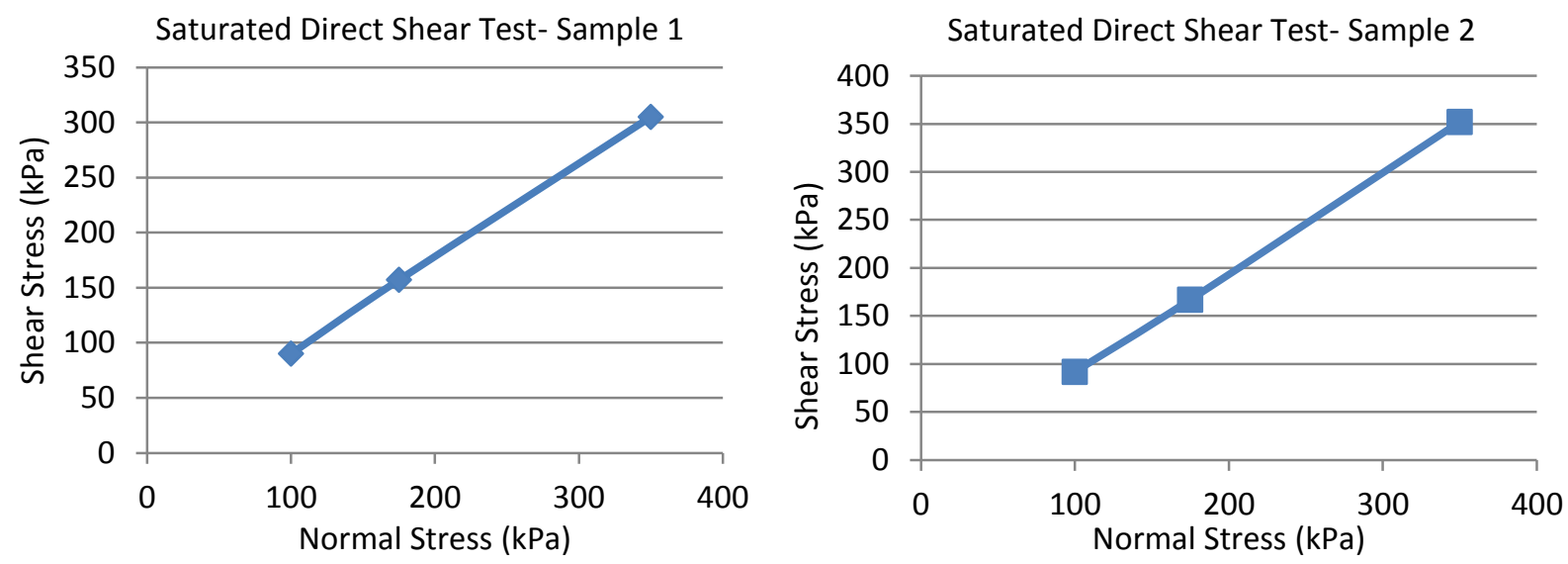

Figure 9 Results of saturated direct shear tests for samples 1 and 2 - normal and shear stress responses

\subsubsection{Direct shear tests for unsaturated samples}

The unsaturated direct shear tests were undertaken using a modified direct shear apparatus similar to Figures 6 (b) and (c), which has the facility to control the pore air pressure and pore water pressure applied to the soil specimen. To control the pore air and water pressures, a porous disc was placed at the top of the specimen and a high air entry disc placed at the bottom. A constant normal stress $\left(\sigma-u_{a}\right)$ of approximately $175 \mathrm{kPa}$ was maintained during the test and matric suctions varying from 0 to $400 \mathrm{kPa}$ were applied to the specimen. The soil specimen was then allowed to come to equilibrium under the applied net normal stress and matric suction. Vertical deflection and water movement were measured until there was no water discharge, after which the specimen was sheared under a constant rate of displacement. The results of matric suction versus shear stress for samples 1 and 2 are summarised in Table 3 . Figure 10 shows the plots of shear stress versus the matric suction which shows a non-linearity in the failure envelope similar to observations by Gan et al. (1988) as a characteristic difference between saturated and unsaturated soil responses to stress state variables. Shear stress response of saturated samples to relevant state variable (net normal stress) is fairly linear, while the unsaturated soil shear stress response to matric suction is clearly curvilinear.

Table 3 Unsaturated direct shear data and stress measurement of tailings

\begin{tabular}{lllll}
\hline & \multicolumn{2}{l}{ Matric suction $\mathbf{( k P a )}$} & \multicolumn{2}{c}{ Shear stress $\mathbf{( k P a )}$} \\
\hline Sample 1 & Stage 1 & 49 & Stage 1 & 175 \\
& Stage 2 & 100 & Stage 2 & 201 \\
Normal stress & Stage 3 & 198 & Stage 3 & 243 \\
fixed at 175 kPa & Stage 4 & 399 & Stage 4 & 282 \\
& Stage 1 & 49 & Stage 1 & 169 \\
Sample 2 & Stage 2 & 100 & Stage 2 & 198 \\
Normal stress & Stage 3 & 198 & Stage 3 & 240 \\
fixed at 175 kPa & Stage 4 & 399 & Stage 4 & 282 \\
\hline
\end{tabular}


Unsaturated Direct Shear Test - with Constant Normal Stress $175 \mathrm{kPa}$-Sample 1

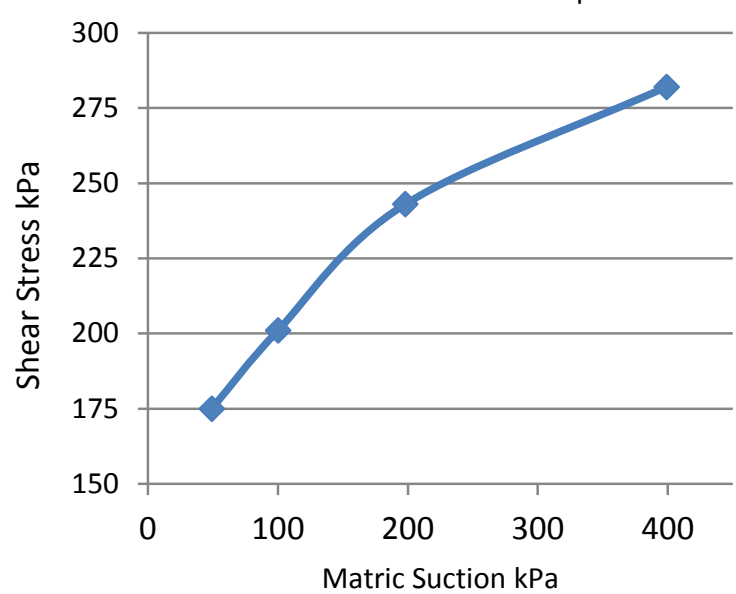

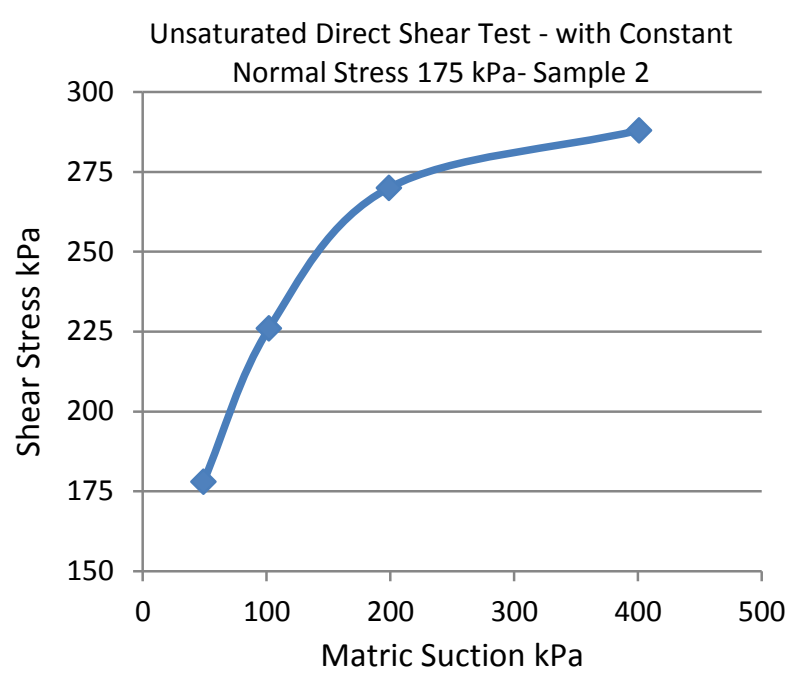

Figure 10 Matric suction versus shear stress obtained from unsaturated direct shear tests

A typical plot of the vertical displacement versus the horizontal displacement curves for all the four stages is shown in Figure 11. The curves generally appear to show that the soil dilated during shear. As higher suctions were applied, the curves show an increase in normal displacement with increasing horizontal displacement.

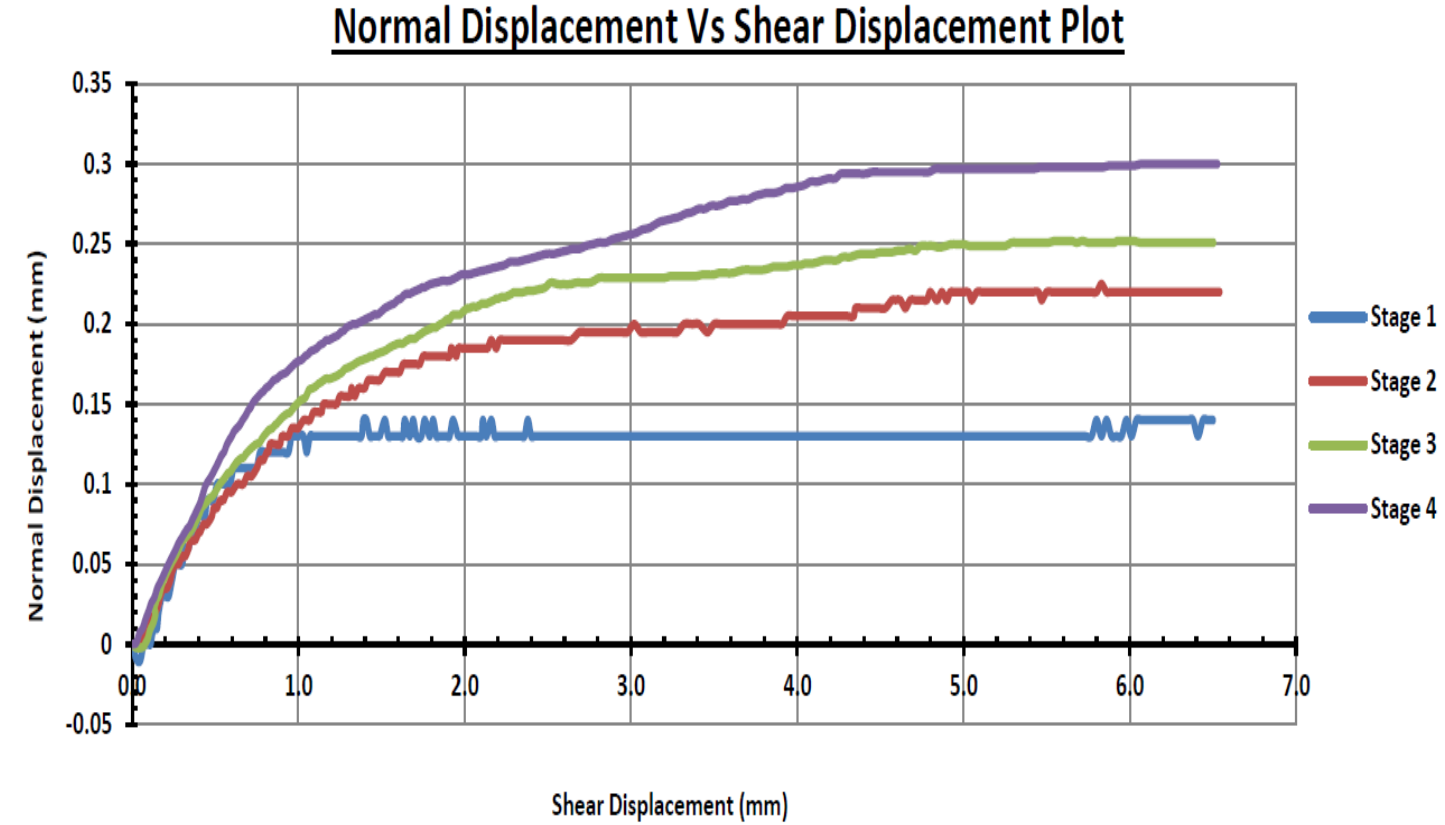

Figure 11 Vertical and shear displacement plots from unsaturated direct shear tests

\section{$5 \quad$ Summary and conclusions}

This paper has presented laboratory tests on the unsaturated properties of magnetite tailings to understand the characteristic differences between the saturated and unsaturated properties, especially the water retention characteristics and strength properties. The SWCC curves consistently show that the magnetite tailings have a relatively low AEV between 15 and $18 \mathrm{kPa}$ and the material desaturates quickly, creating large matric suction and negative pore pressures which may require a large amount of rainfall flux over a long period to dissipate. This potentially explains the negative pore pressures consistently obtained from historical field CPTus in the dry stack facility.

Triaxial and direct shear test results confirm the difference between shear strength responses of saturated and unsaturated tailings to stress state variables (net normal stress and matric suction). For the saturated 
tests, the tailings shear stress response to the net normal stress is fairly linear. For the unsaturated tailings, the shear stress versus matric suction shows non-linearity in the failure envelope. Higher shear strengths are obtained due to matric suction which explains why high stacking angles up to $44^{\circ}$ are achieved onsite.

The investigations show that in unsaturated filtered tailings with a low AEV and in low rainfall areas with high evaporation, large matric suctions develop. These suctions may govern dry stack hydraulic and shear strength performance.

\section{References}

Amoah, N 2017, 'Filtered tailings and dry stack facility at Karara Mine - design and operational overview', presentation from Tailings Management Practical Considerations, Perth, 26-28 April 2017.

ANCOLD 2012, Guidelines on Tailings Dam Design, Construction and Operation, ANCOLD, Hobart.

Davies, M 2011, 'Filtered tailings - the fundamentals', Proceedings of Tailings and Mine Waste 2011, Norman B. Keevil Institute of Mining Engineering, Vancouver.

Fredlund, DG \& Morgenstern, NR 1977, 'Stress state variables for unsaturated soils', Journal of the Geotechnical Engineering Division, vol. 103, GT5, pp. 447-466.

Fredlund, DG \& Xing, A 1994, 'Equation for the soil-water characteristic curve', Canadian Geotechnical Journal, vol. 31, no. 4, pp. 521-532.

Fredlund, DG \& Rahardjo, H 1993, Soil Mechanics for Unsaturated Soils, John Wiley \& Sons, New York.

Fredlund, DG, Morgenstern, NR \& Widger, RA 1978, 'The shear strength of unsaturated soils', Canadian Geotechnical Journal, vol. 15, no. 3, pp. 313-321.

Fredlund, DG, Xing, A, Fredlund, MD \& Barbour, SL 1996, 'The relationships of the unsaturated soil shear strength to the soil-water characteristic curve', Canadian Geotechnical Journal, vol. 33, pp. 440-448.

Fredlund, DG, Rahardjo, H, Leong, EC\& Ng, CWW 2001, 'Suggestions and recommendations for the interpretation of soil-water characteristic curves', in KKS Ho and KS Li (eds), Proceedings of the 14th Southeast Asian Geotechnical Conference, Swets and Zeitlinger, Lisse, pp. 503-508.

Gan, JK \& Fredlund, DG 1996, 'Shear strength characteristics of two saprolitic soils', Canadian Geotechnical Journal, vol. 33, pp. 595-609.

Gan JK, Fredlund, DG \& Rahardjo, H 1998, 'Determination of shear strength parameters using direct shear test', Canadian Geotechnical Journal, vol. 25, no. 8, pp. 500-510.

Ho, DYF \& Fredlund, DG 1982, 'A multistage triaxial test for unsaturated soils', Geotechnical Testing Journal, vol. 5, no. 1/2, pp. 18-25.

Kim, BS, Takeshita, Y, Kato, S \& Parl, SW 2016, 'Effect of fine grain contents on the unsaturated mechanical characteristics of embankment materials', Proceedings of the 6th Asia Pacific Conference on Unsaturated Soils, Z Chen, C Wei, D Sun and X Xu (eds), Taylor \& Francis, London, pp. 281-286.

Kohgo, Y 2003, 'Review of constitutive models for unsaturated soils and initial-boundary value analyses', Proceedings of the 2nd Asian Conference on Unsaturated Soils: UNSAT-ASIA 2003, pp. 21-40.

Lupo, J 2010, 'Dry stack tailings, design considerations', Proceedings of Tailings and Mine Waste 2010, CRC Press, Boca Raton, pp. 327-334.

Lu, N 2008, 'Is matric suction a stress variable?', Journal of Geotechnical and Geoenvironmental Engineering, vol. 134, no. 7, pp. 899-905.

Schnellmann, R, Rahardjo, H \& Schneider, HR 2013, 'Unsaturated shear strength of a silty sand', Engineering Geology, vol. 162, pp. 88-96.

Vanapali, SK, Fredlund, DG, Pufahl, MD \& Clifton, AW 1996, 'Model for prediction of shear strength with respect to soil suction', Canadian Geotechnical Journal, vol. 33, no. 3, pp. 379-302.

Zhou, A, Huang, R \& Sheng, D 2016, 'Capillary water retention curve and shear strength of unsaturated soils', Canadian Geotechnical Journal, vol. 53, no. 6, pp. 974-987. 